\title{
Synthesis of Carbon Nanotubes by Molten Salt Technique
}

\author{
S ANAGAPPAN ${ }^{\mathrm{a}^{*}}$, V. THIRUMAL ${ }^{\mathrm{b}}, \mathrm{K}$. RAMKUMAR ${ }^{\mathrm{b}}$ and A VISUVASAM ${ }^{\mathrm{a}}$

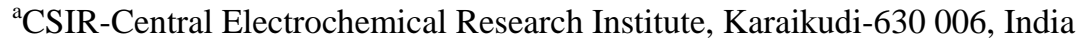 \\ ${ }^{\mathrm{b}}$ Department of Nanoscience and Technology, Alagappa University, \\ Karaikudi- 630 003, India \\ angs67@gmail.com
}

Received 21 September 2012 / Accepted 20 October 2012

\begin{abstract}
Electrolytically prepared carbon nanotubes (CNTs) were obtained from normal graphite in $\mathrm{LiCl}-1 \% \mathrm{SnCl}_{2}$ melt at $600{ }^{\circ} \mathrm{C}$ about $5 \mathrm{~h}$. The carbon consumption for nanotube formation was observed visually and the same may occurs at the graphite cathode due to erosion during the electrolysis. X-Ray diffraction (XRD) and scanning electron microcopy (SEM) studies have shown similar features between these electrolytic carbon nanotubes and those prepared by other methods. In addition, it has been noticed that the temperature and nature of the molten salts play an important role in determining the quantity and quality of the graphite-nanotube conversion.
\end{abstract}

Keywords: Carbon nanotubes, Graphite, Molten salts, Electrolysis, XRD, SEM.

\section{Introduction}

Carbon nanotubes (CNTs) were discovered in 1991 by Japanese electron microscopist Sumio-Iijima, who was studying the material deposited on the cathode during the arcevaporation synthesis of fullerenes ${ }^{1}$. They can be classified into single walled carbon nanotubes (SWCNT), multi walled carbon nanotubes (MWCNT) and each has its advantages and disadvantages depending upon the application in which to be used. Based on the geometrical structures, single walled carbon nanotube (SWCNT) can be classified into Armchair, Zig-zag and Chiral (helical) nano-tubes. These tubes consist of rolled up hexagons, depending upon the size of graphene area folded onto a cylinder, nano-tubes of different radii are obtained. These tubes are extremely long and possess different symmetry. CNTs have very interesting physicochemical properties such as ordered structure with high aspect ratio, ultra light weight, high mechanical strength, high electrical conductivity, high thermal conductivity, metallic or semi metallic behaviour and high surface area ${ }^{2-15}$. Singlewalled carbon nanotubes (SWCNTs), with a diameter in the nanometer range and a length of several micrometers, are especially attractive for that purpose due to their highly desirable mechanical, thermal, electrical and magnetic properties. CNTs have added applications in recent years such as fillers in polymer composites, field emitters for flat panel displays, electrodes for supercapacitors and elements in nanoelectronics - field effect transistors, 
room-temperature based single-electron transistors, logic gate circuits, inverters, electromechanical switches and prototypes of memory devices based on SWCNifid effect

transistors ${ }^{16-20}$. Recent development in research showed a promising for carbon nanotubes in bulk quantities for not only electron conduction in insulating phases, but also energy conversion and storage. In particular, it has been demonstrated that supercapacitors based on carbon nanotubes exhibit high capacitance (high pulsed power) and long cycle life. The curved CNTs enable a much greater flexibility for chemical modifications of the nanotubes surface to suit various practical applications. Most commonly CNTs synthesis methods are electric discharge, chemical vapor deposition (CVD) and laser ablation ${ }^{21-28}$. Generally these routes produce only low yields and are relatively expensive, although the quality of the product is high.

ONE of the most outlook methods is to produce carbon nanotubes in bulk quantities by molten salt technique. A newly developed recent development in electrolytic formation of carbon nanotubes in molten salts was discovered by Hsu, Kroto and their coworkers of Sussex University in the UK in 1995. The electrolytic method is the first example of CNTs is being produced in the condensed phase ${ }^{29}$. Around the world in the past few years, the process of CNTs from molten melt is being reduction of gathering forces. More impartment the cost for the energy consumption of electrolysis is very low in comparison with that material consumption, i.e. graphite and molten salt. In addition to the low energy consumption and use of cheap raw materials the electrolytic method has the advantage of being potentially continuous process. Electrolytic produced CNTs yield was mainly depend strongly on electrolysis, time, current, voltage and temperature of the bath. The electrolytic CNTs will become gradually more attractive because of the device and operational simplicity and feasible continuity method. Electrolytic CNTs preparation can have promising in future and compete with other CNT production technologies ${ }^{30}$.

Recently carbon nanotubes filled with $\mathrm{Sn}$ is attracted an extensive interest in various applications, particularly for the lithium intercalation electrode in lithium ion batteries. New method of producing Sn-filled carbon nanotubes by electrolysis of graphite electrode in LiCl$1 \% \mathrm{SnCl}_{2}$ molten melts, with a high overall yield and the filled CNTs were also formed by the electrolytic method ${ }^{31-33}$. The present investigation deals with the CNT formation through the electrolytic method in $\mathrm{LiCl}-1 \% \mathrm{SnCl}_{2}$ melt both for filtration and precipitated samples.

\section{Experimental}

Commercial graphite both as the cathode and anode materials of the EC4 grade were taken for the study. The graphite rod for cathode material (high purity carbon rod) of height $5 \mathrm{~cm}^{2}$ and diameter $1.4 \mathrm{~cm}^{2}$ and the graphite crucible for anode of height $8 \mathrm{~cm}^{2}$ and diameter $5 \mathrm{~cm}^{2}$ were taken. The electrolysis was carried out for $5 \mathrm{~h}$ by using the molten Lithium chloride ( $\mathrm{LiCl}$ ) with $1 \%$ Tin chloride $\left(\mathrm{SnCl}_{2}\right)$. The inert gas argon was purged throughout the experiment to remove the moisture from the salt and away the oxidation of graphite materials. The carbon nanotubes separations were done by water-water interface and watertoluene interface ${ }^{34-37}$. Differential thermal analysis and thermo gravimetric analysis (TGA/DTA) of the samples were done using Rigaku Thermal-plus TG 8120. The phase formation and the structural details of the synthesized compounds were characterized by $\mathrm{X}$-ray powder diffraction (XRD) using $\mathrm{CuK} \alpha(\lambda=1.541 \AA)$ radiation with $2 \theta$ value range of 20 to 90 using PAnalytical X'pert powder diffractometer. The Fourier transform infrared (FTIR) spectra were recorded in the range of 400 to $4000 \mathrm{~cm}^{-1}$ using Perkin Elmer UK Paragon - 500 spectrometer. Scanning electron microscope (SEM) was employed for the morphological studies using JEOL JSM 3.5 CF Japan make model. 


\section{Synthesis}

Alkali and alkaline earth chloride salts are usually hygroscopic. Thermally drying $\left(250{ }^{\circ} \mathrm{C}\right)$ the salt in air can usually be satisfactory for CNTs preparation. (For CNT preparation, because of the use of graphite crucible, melting the salt should be conducted under inert atmosphere). The experiments were conducted at temperatures slightly above the melting point of $\mathrm{LiCl}\left(600{ }^{\circ} \mathrm{C}\right)$. To prepare the sample approximately, the mixture consists of $\mathrm{LiCl}-1 \% \mathrm{SnCl}_{2}$ was taken in a graphite crucible. The graphite crucible was placed in an electrical heated furnace and the temperature level set at $600{ }^{\circ} \mathrm{C}$. The free flowing argon gas was passed onto the furnace throughout the experiment to reduce the oxidation of salt and carbon materials.

The temperature reached to $600{ }^{\circ} \mathrm{C}$ and to equilibrate the melt for $1 \mathrm{~h}$. This process was called pre-electrolysis. After the pre-electrolysis, graphite rod of $1.4 \mathrm{~cm}^{2}$ diameter with $5 \mathrm{~cm}^{2}$ height was inserted into the melt as cathode. The cathode was inserting into the melt up to $4 \mathrm{~cm}^{2}$ depths in the graphite crucible as anode as well as holding vessel for electrolyte. The control of DC power supply also needs to provide a sufficiently wide range of currents and voltages. This experiment was carried out at the constant current 3A, and voltage 4.6 V. The current, voltage and temperature of the bath are recorded throughout the experiment.

\section{CNT-Purification}

After the electrolysis, the cathode was removed from the reactor. Upon removal from the reactor, it was usually observed that the lower end of the covered cathode was eroded. The erosion occurs with the nature and degree of erosion depending up on the experimental conditions $^{38}$. The erosions occurred in two different ways. Under high current density or voltage, the remaining cathode shows as in the Figure 1 (flat surfaces and cracks) that apparently resulted from cracking. If a relatively small current density or voltage was applied, the erosion could be uniform, and the cathode only became thinner. After removal of the cathode, the furnace is allowed to cool naturally to room temperature or a temperature below $300{ }^{\circ} \mathrm{C}$. So that, once taken out of the reactor, the holding vessel containing the solidified salt can be safely and quickly cooled in air.

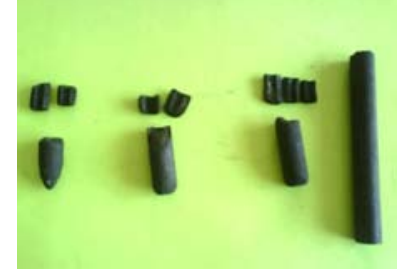

Figure 1. Flat surfaces and cracks in remaining cathodes

The carbon nanomaterials were separated by washing with toluene and water. The electrolytic carbon nanomaterials aggregated at the interface of toluene-water suggests the existence of either separated hydrophobic and hydrophilic groups on the surface of the carbon nanomaterials. First washing with water and kept for $1 \mathrm{~h}$, the precipitate was obtained. After settling the carbon materials precipitation in bottom, excess amount of water were removed. And then washing with water 3 or 4 times will remove the chlorides. The washed carbonaceous materials were added to a mixture of 1:10 toluene/water contained in a separation flask. The well mixed carbon materials suspension from top of the flask followed by the toluene was slowly evaporated. The black suspension was left to stand overnight to allow precipitation of the carbonaceous materials, followed by decanting the clear water or simply filtered through filter paper. The obtained black precipitate or powdery product, followed by the washing step 
was sometimes repeated to achieve more complete removal of the salt from the carbon product. The filtration and precipitated samples henceforth called as CNT-f and CNT-p respectively.

\section{Results and Discussion}

Figure 2 show that the TGA/DTA scan of the CNT-f to elucidate the thermal process in $\mathrm{LiCl}-1 \% \mathrm{SnCl}_{2}$ melts. The first weight loss at $366{ }^{\circ} \mathrm{C}$ of about $9.4 \mathrm{wt} \%$ always with a sharp turn, which can be assigned to the loss of $\mathrm{H}_{2}$ generated from $\mathrm{CH}_{\mathrm{x}}$ species during their conversion to nanocarbons ${ }^{39}$. Further weight losses at $472{ }^{\circ} \mathrm{C}$ (weight loss $39.3 \mathrm{wt} \%$ ), $537.3{ }^{\circ} \mathrm{C}$ (weight loss 49.2 wt \%) and $658.3{ }^{\circ} \mathrm{C}$ (weight loss 58.3 wt \%) are due to the decomposition of structurally transformed graphite to CNT formation at higher temperatures ${ }^{40}$. In good agreement, a large exothermic peak is observed starting from $347.4{ }^{\circ} \mathrm{C}$ to $524.1{ }^{\circ} \mathrm{C}$ by DTA, which corresponds to the formations of CNTs. From the Figure 3, the DSC study for CNT-f reveals the region of the glass transition temperature, $\mathrm{T}_{\mathrm{g}}$ and the region of the melting temperature, $\mathrm{T}_{\mathrm{m}}$. The peak at $444{ }^{\circ} \mathrm{C}$, a sharp exothermic behavior $(7.5 \mathrm{KJ} / \mathrm{g})$ is assigned to the glass transition temperature. The peak at $597{ }^{\circ} \mathrm{C}$, a broad exothermic behavior $(2.4 \mathrm{KJ} / \mathrm{g})$ is assigned to melting temperature of CNT.

Figure 4 shows that the TGA/DTA curve for the CNT- p was prepared by molten salt technique in $\mathrm{LiCl}-1 \% \mathrm{SnCl}_{2}$ melt. The peak at $85.4{ }^{\circ} \mathrm{C}$ (weight loss $3.0 \mathrm{wt} \%$ ) is attributed to evaporations of small amount of inbound water in the salt. After the dehydration, the net weight loss accounted at $374.5^{\circ} \mathrm{C}$ (weight loss $8.7 \mathrm{wt} \%$ ) which can be assigned to the loss of $\mathrm{H}_{2}$ generated from $\mathrm{CH}_{\mathrm{x}}$ species during their conversion to nanocarbons. The weight losses at $481{ }^{\circ} \mathrm{C}$ (weight loss $31.5 \mathrm{wt} \%$ ), $552.8^{\circ} \mathrm{C}$ (weight loss $37.7 \mathrm{wt} \%$ ), $634.8{ }^{\circ} \mathrm{C}$ (weight loss $49.4 \mathrm{wt} \%$ ) and $737.3{ }^{\circ} \mathrm{C}$ (weight loss $56.4 \mathrm{wt} \%$ ) are due to the decomposition of structurally transformed graphite to CNTs formation. A sharp exothermic peak centered at $457^{\circ} \mathrm{C}$, from $348.9{ }^{\circ} \mathrm{C}$ to $530.3{ }^{\circ} \mathrm{C}$ in the DTA curve confirmed the CNT formation. Figure 5 shows the DSC curve for the CNT-p was prepared by molten salt technique in the $\mathrm{LiCl}-1 \% \mathrm{SnCl}_{2}$ melt. The exothermic peak at $456{ }^{\circ} \mathrm{C}$ is exactly match with the DTA curve (exothermic peak at 457 ${ }^{\circ} \mathrm{C}$ ) is assigned to $\mathrm{CNT}$ formation around $5.4 \mathrm{KJ} / \mathrm{g}$ heat capacity. This peak exist the glass transition temperature of graphite to CNTs formation. The peak at $607.9{ }^{\circ} \mathrm{C}$, an exothermic peak is attributed to the melting temperature of CNT about $3.2 \mathrm{KJ} / \mathrm{g}$ heat capacity.

The XRD pattern of CNT-f was prepared by molten salt technique in the $\mathrm{LiCl}-1 \% \mathrm{SnCl}_{2}$ melts is shown in Figure 6. The peak at $26.5^{\circ}$ confirms the CNT formation in the (002) plane. The peaks at $43.2^{\circ}, 46.6^{\circ}, 54.5^{\circ}, 57.6^{\circ}, 59.3^{\circ}, 77.4^{\circ}$ are assigned to hexagonal structure of nanocarbon. Some impurities are present in the sample as $\mathrm{LiCl}$ and $\mathrm{SnCl}_{2}$. Figure 7 shows the XRD pattern of CNT-p was prepared by molten salt method. The peak at $26.5^{\circ}$ confirms the CNT formation in the (002) plane. The peaks at $32^{\circ}, 36.2^{\circ}, 43.4^{\circ}, 44.7^{\circ}, 46.7^{\circ}, 54.7^{\circ}$ and $88.5^{\circ}$ are assigned to the hexagonal nanocarbon in the planes (220), (210), (101), (004) and (006) respectively. Some impurities are present in the sample like $\mathrm{SnO}_{2}, \mathrm{SnCl}_{2}$. The peak at $20.7^{\circ}$ is assigned to $\mathrm{C}_{60}$.

Figure 8 shows the FTIR scan for CNT-f was carried out in the range of $400-4000 \mathrm{~cm}^{-1}$. The dominant peaks at 1426, $3390 \mathrm{~cm}^{-1}$ corresponds to $\mathrm{C}-\mathrm{C}$ bonding, O-H stretching vibrations respectively. The peak at $2409 \mathrm{~cm}^{-1}$ corresponds to the C-O bonds and the features between 2854 and $2920 \mathrm{~cm}^{-1}$ are consistent with $\mathrm{C}-\mathrm{H}_{\mathrm{x}}$ stretching vibrations of chemisorbed hydrogen of various types of $\mathrm{CNT}^{41-43}$. The band at $714 \mathrm{~cm}^{-1}$ corresponds to (C-C) bending vibrations.

The FTIR spectrum for the CNT-p was carried out in the range of $400-4000 \mathrm{~cm}^{-1}$ is shown in Figure 9. The dominant peak at $1423 \mathrm{~cm}^{-1}$ corresponds to the CNT vibrational modes ${ }^{43}$. The peaks between 3412 and $3445 \mathrm{~cm}^{-1}$ are consistent with $\mathrm{O}-\mathrm{H}$ stretching vibrations ${ }^{44}$. The peak at $2925 \mathrm{~cm}^{-1}$ is attributed to $\mathrm{C}-\mathrm{H}_{\mathrm{x}}$ stretching vibrations of chemisorbed hydrogen. The peaks at 1577 and $2362 \mathrm{~cm}^{-1}$ are attributed to $\mathrm{C}=\mathrm{O}$ stretching, $\mathrm{C}-\mathrm{O}$ bond respectively ${ }^{43,44}$. 


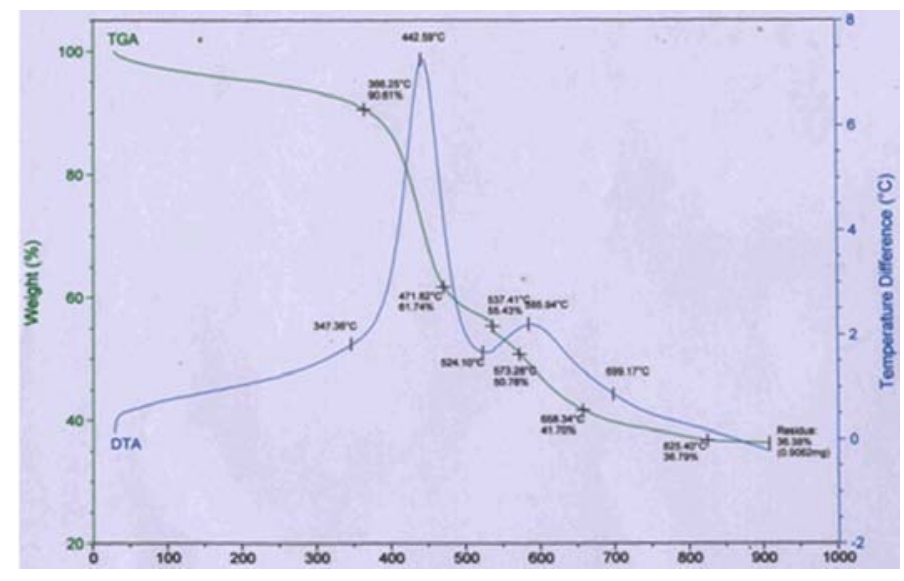

Figure 2. TGA/DTA Curve for CNT $-\mathrm{f}$

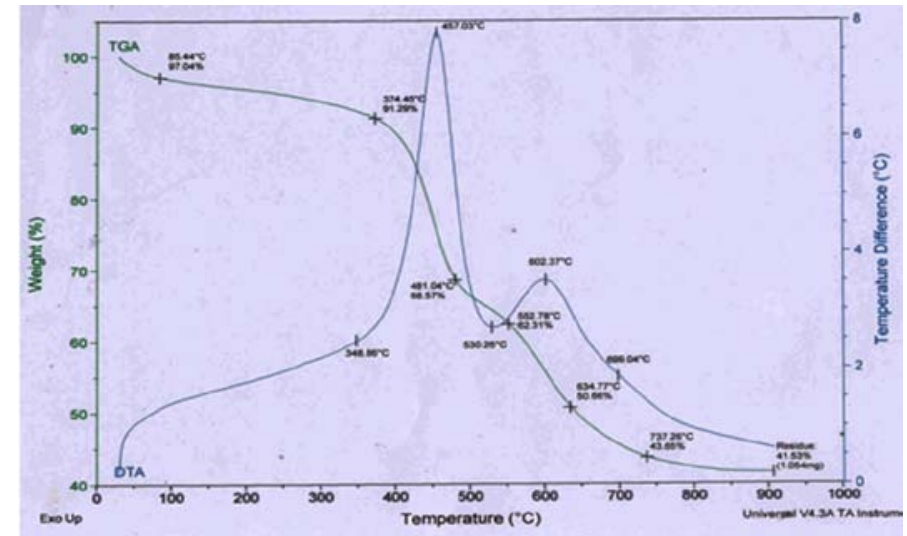

Figure 4. TGA/DTA curve for CNT-p

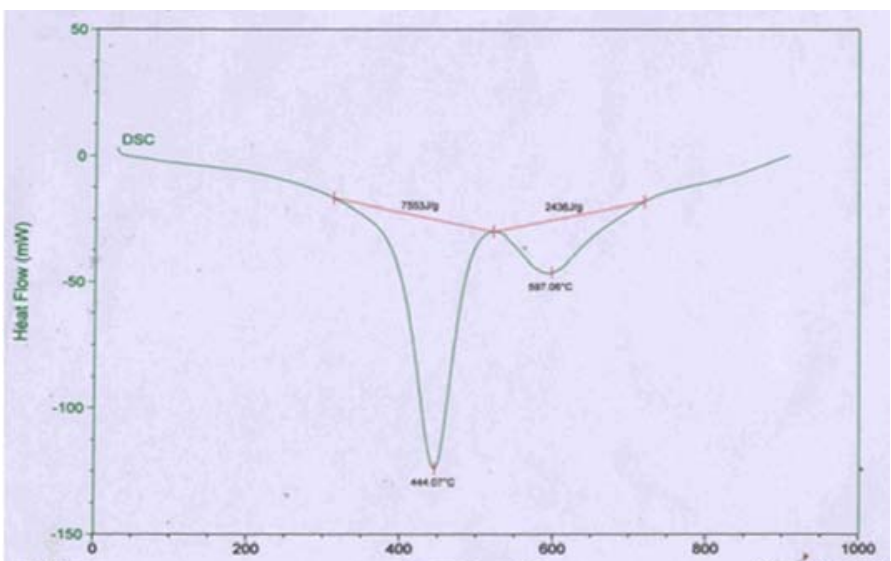

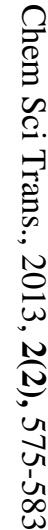

Figure 3. DSC curve for CNT-f

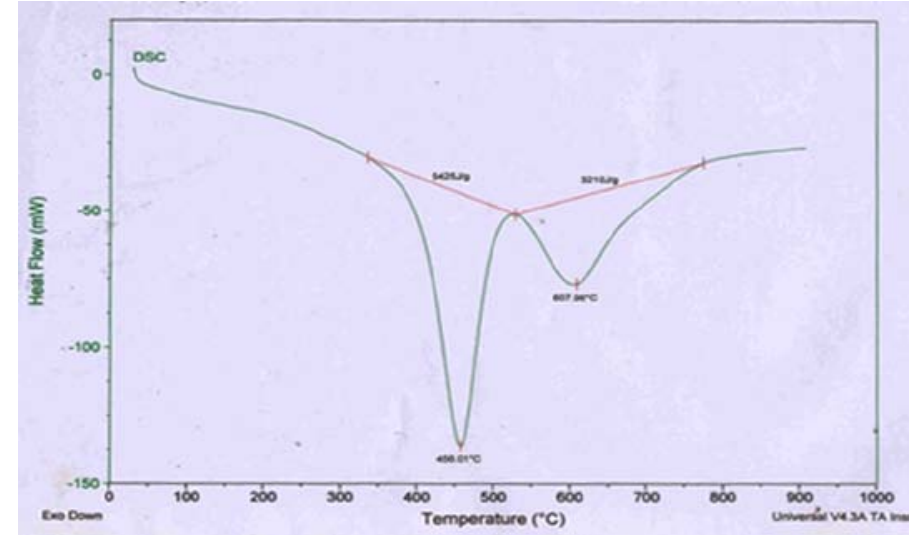

Figure 5. DSC curve for CNT-p 


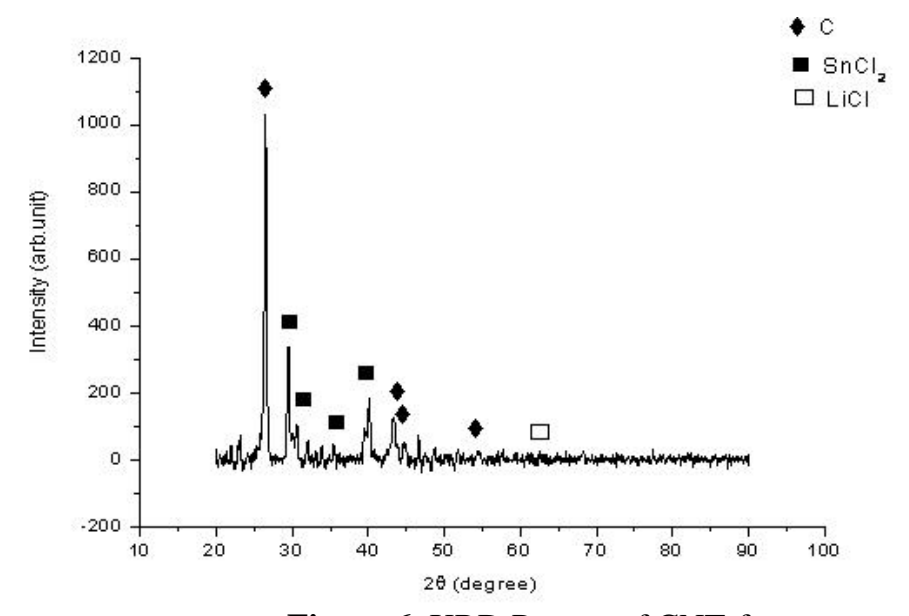

Figure 6. XRD Pattern of CNT-f

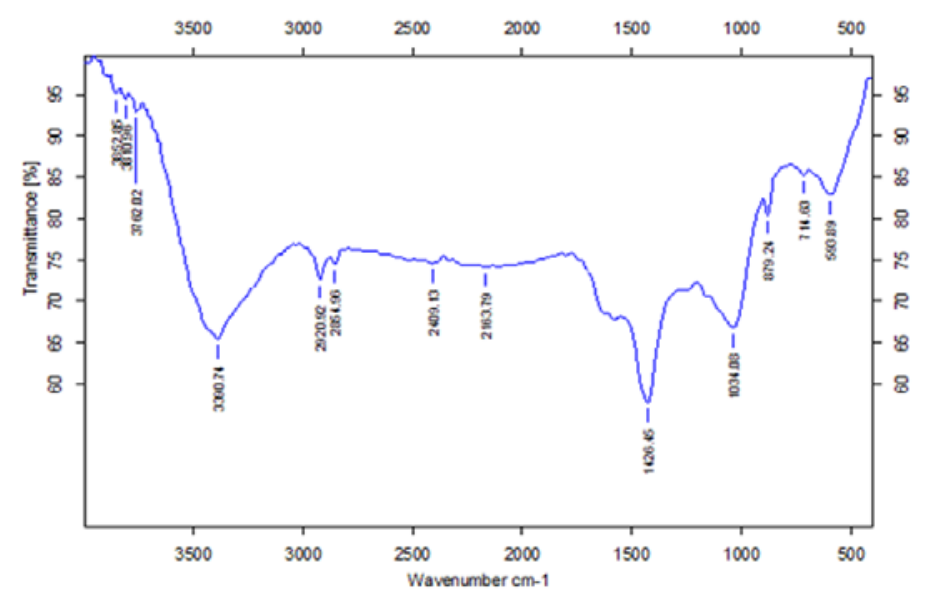

Figure 8. FTIR curve for CNT-f

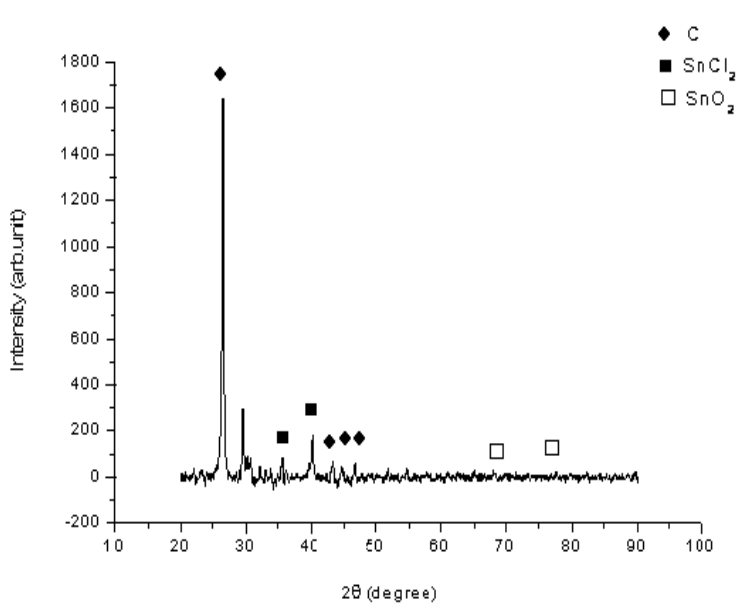

Figure 7. XRD pattern of CNT-p

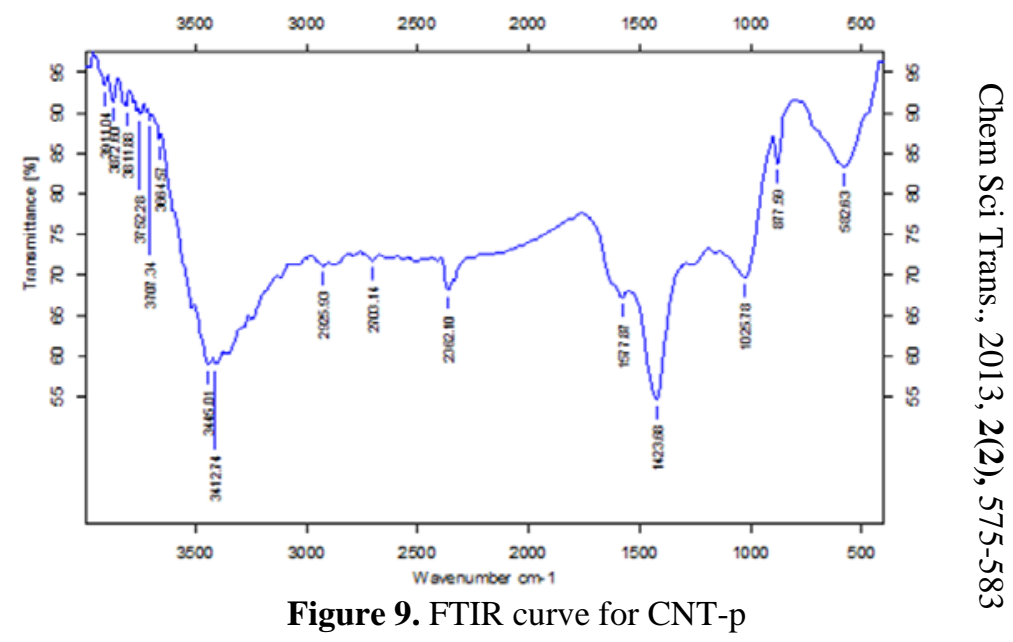


The SEM image of CNT-f is shown in Figure 10. It shows that a tube like structure "grown out" from the cathode surface. The formed nanotubes are usually curved. The material extracted from $\mathrm{LiCl}-1 \% \mathrm{SnCl}_{2}$ electrolyte contains a moderate amount of carbon nanotubes with a diameter of 100-200 $\mathrm{nm}$ and lengths up to 8-14 $\mu \mathrm{m}$. According to the energy dispersive analysis (EDX, Figure 11) the sample consists of moderate carbon, some traces of oxygen, iron, chloride and copper were observed. EDX analysis further confirmed that the nanotubes were not composed of tin. Figure 12 shows that the SEM image of the CNT-p was achieved by using water/toluene interface. Interestingly, toluene is usually used as a separating agent for nanotubes ${ }^{45}$. The obtained product morphology is different from filtration sample those observed previously with shape like sheets of flowers, and very small nanotubes. Impurities such as $\mathrm{SnCl}_{2}$ and $\mathrm{SnO}_{2}$ were originating from the salt. According to the energy dispersive analysis (EDX, Figure 13) the sample consist of moderate carbon, some traces of oxygen, iron, chloride, calcium and Si were present.

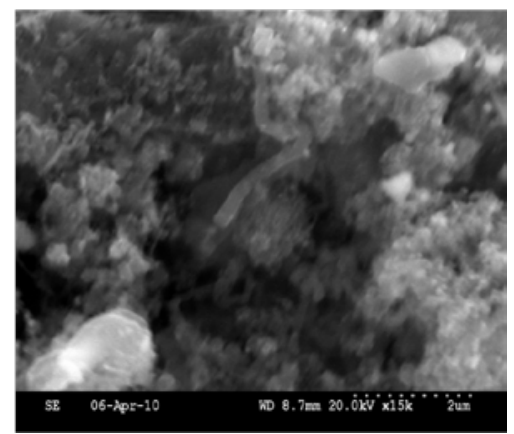

Figure 10. SEM images of CNT f

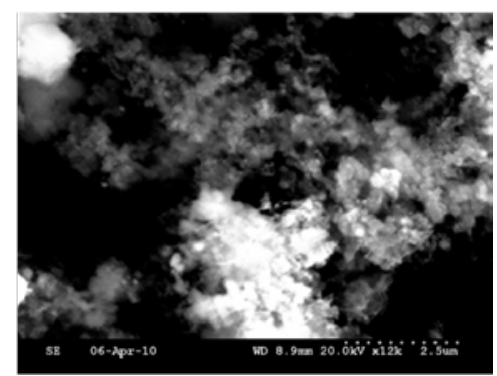

Figure 12. SEM images of CNT-p
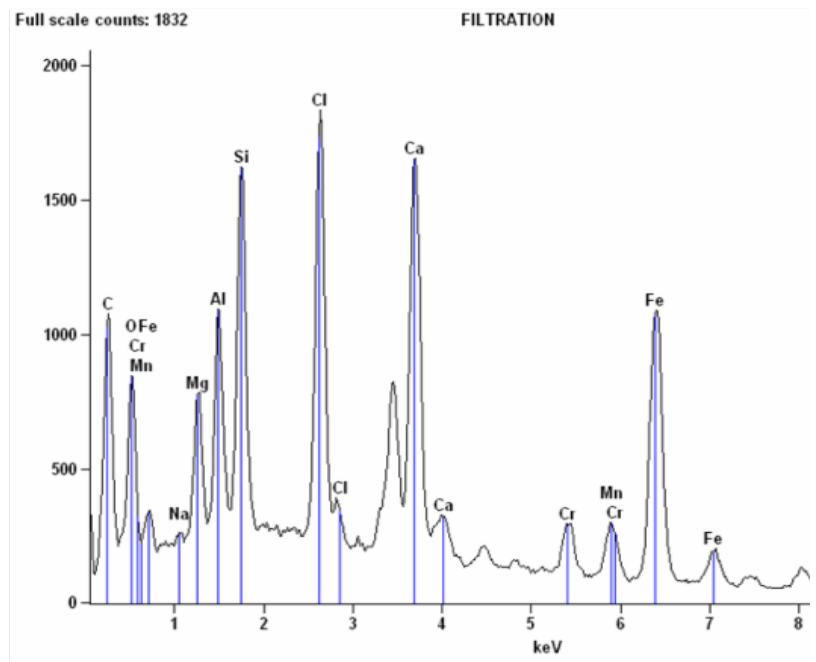

Figure 11. EDX for CNT-f

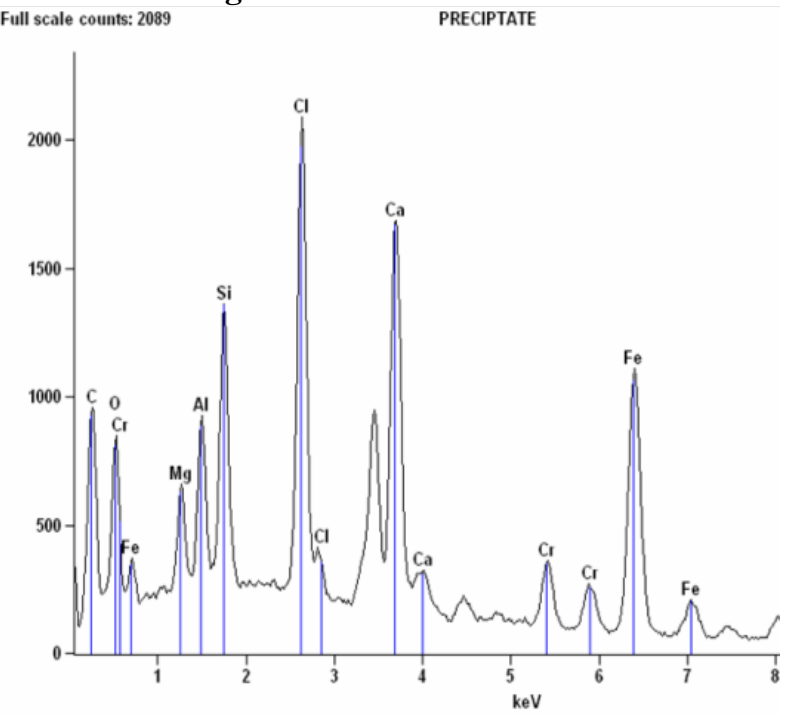

Figure 13. EDX for CNT-p 


\section{Conclusion}

CNT was successfully prepared by molten salt technique from $\mathrm{LiCl}-1 \% \mathrm{SnCl}_{2}$ melts. A large exothermic peak is observed for the CNT-f from $347.4{ }^{\circ} \mathrm{C}$ to $524.1{ }^{\circ} \mathrm{C}$ by DTA, which corresponds to the formation of CNT. A sharp exothermic peak is centered at $457^{\circ} \mathrm{C}$ from $348.9{ }^{\circ} \mathrm{C}$ to $530.3{ }^{\circ} \mathrm{C}$ in the DTA curve confirmed that the CNT formation from the CNT-p. From the XRD, the peak at $26.5^{\circ}$ confirms the CNT formation in the 002 plane for both CNT-f and CNT-p. The FTIR results revealed that the CNT vibrational modes assigned to 1426 and $1423 \mathrm{~cm}^{-1}$ for CNT-f and CNT-p respectively. The morphology indicated that a moderate amount of carbon nanotubes with a diameter of the order of 100-200 nm and lengths up to 8-14 $\mu \mathrm{m}$. For CNT-f, the EDX analysis is further confirmed that the nanotubes are not composed of tin.

\section{Acknowledgment}

The authors are thanks to the Director, CSIR-CECRI for his constant encouragement and staff of Electropyrometallurgy Division for their help.

\section{References}

1. Iijima S, Nature, 1991, 354, 56.

2. Kroto H W, Heath J R, O’Brien S C, Curl R F and Smalley R E C, Nature, 1985, 318, 162.

3. $\quad$ Sinnott S B, J Nanosci Nanotechnol., 2002, 2, 113-123.

4. Treacy M M J, Ebbesen T W and Gibson J M, Nature, 1996, 381, 678-680.

5. $\quad$ Lourie O and Wagner H D, J Mater Res., 1998, 13, 2418.

6. Jin Z, Pramoda K P, Xu G and Goh S H, Chem Phys Lett., 2001, 337, 43.

7. Takaba H, Katagiri M, Kubo M, Vetrivel R and Myamoto A, Microporous Mater., 1995, 3, 449.

8. Tanaka K, Okahara K, Okada M and Yamabe T, Chem Phys Lett., 1992, 191, 469-472.

9. Robertson D H, Brenner D W and Mintmire J W, Phys Rev B, 1992, 45(21), 12592-12595.

10. Ajayan P M and Iijima S, Nature, 1993, 361, 333-334.

11. Ajayan P M, Stephan O, Colliex C and Trauth D, Science, 1994, 265, 1212-1214.

12. Ajayan P M, Schadler L S, Ginnaris C and Rubio A, Adv Mater., 2000, 12(10), 750-753.

13. Ni B and Sinnott S B, Phys Rev B, 2000, 61, R16343.

14. Lau K T and Hui D, Carbon, 2002, 40, 1605-1606.

15. Sandler J, Shaffer M S P, Prasse T, Bauhofer W, Schulte K and Windle A H, Polymer, 1999, 40, 5967.

16. Haggenmuller R, Gommans H H, Rinzler A G, Fischer J E and Winey K I, Chem Phys Lett., 2000, 330, 219-225.

17. Biercuk M J, Llaguno M C, Radosavljevic M, Hyun J K, Johnson A T and Fischer J E, Appl Phys Lett., 2002, 80, 2767-2739.

18. Sarno M, Gorrasi G, Sannino D, Sorrentino A, Ciambelli P and Vittoria V, Macro Rapid Comm., 2004, 25, 1963.

19. Harris P J, Carbon Nanotubes and Related Structures: New Materials for the $21^{\text {st }}$ Century, University press, Cambridge, 1999.

20. Tans S J, Verschueren A R M and Dekker C, Nature, 1998, 393, 49-51.

21. Hughes M, Shaffer M S P, Renouf A C, Singh C, Chen G Z, Fray D J and Windle A H, Adv Mater., 2002, 14, 382. 
22. Terrones M, Annu Rev Mater Res., 2003, 33, 419-501.

23. Baughman R H, Zakhidov A A and de Heer W A, Science, 2002, 297, 787-792.

24. Ajayan P M and Ebbesen T W, Rep Prog Phys., 1997, 60, 1025.

25. Subramoney S, Adv Mater., 1998, 10(15), 1157-1171.

26. Ebbesen T W and Ajayan P M, Nature, 1992, 358, 220-222.

27. Thess A, Lee R, Nikolaev P, Dai H, Petit P, Robert J, Xu C, Lee Y H, Kim S G, Rinzler A G, Colbert D T, Scuseria G E, Tomanek D, Fischer J E and Smalley R E, Science, 1996, 273, 483.

28. Journet C, Maser W K, Bernier P, Loiseau A, de la Chapelle M L, Lefrant S, Deniard P, Lee R and Fischer J E, Nature, 1997, 388, 756-758.

29. (a) Ivanoy V, Fonseca A, Nagy J B, Lucas A, Lambin P, Bernaerts D and Zhang X B Catalytic production and purification of nanotubes having fullerene scale diameters, In: Endo M, Iijima S and Dresselhaus M S (Eds.), carbon nanotubes, Pergamon Oxford UK, 1996, 15; (b) Huang S, Mau A W H, Turney T W, White P A and Dai L $J$ Phys Chem B, 2000, 104, 2193.

30. Chen G Z and Fray D J, J Min Metall B, 2003, 39(1-2), 309-342.

31. Dimitrov A T, Chen G Z, Kinloch I A and Fray D J, J Electrochem Acta, 2002, 48(1), 91-102.

32. Fan S, Chapline M G, Franklin N R, Tombler T W, Cassel A M and Dai H, Science, 1999, 283, 512-514.

33. Geckeler K E and Rosenberg E, (Eds), Functional nanomaterials, American Scientific Publishers (APS) California USA, 2006, 317.

34. Hsu W K, Hare J P, Terrones M, Kroto H W, Walton D R M and Harris P J F, Nature, 1995, 377, 687.

35. Hsu W K, Terrones M, Hare J P, Terrones H, Kroto H W and Walton D R M, Chem Phys Lett., 1996, 262, 161.

36. Chen G Z, Fan X, Luget A, Shaffer M S P, Fray D J and Windle A H, J Electroanal Chem., 1998, 446, 1.

37. Chen G Z, Kinloch I, Shaffer M S P, Fray D J and Windle A H, High Temp Mater Process., 1998, 2, 459.

38. (a) Fray D J, High Temp Mater Process., 1999, 3, 67; (b) Fray D J, Molten Salt Bull., 1999, 66, 2.

39. Ji L, Lin J and Zeng H C, Chem Mater., 2000, 12(11), 3466.

40. Titus E, Ali N, Cabral G, Gracio J and Ramesh Babu P, J Mater Engg Perform., 2006, 15(2), 182-186.

41. Yu G Q, Lee S H and Lee J J, Diamond Relat Mater., 2002, 11, 1633-1637.

42. Ristein J, Stief R T, Ley L and Beyer W, J Appl Phy., 1998, 84, 3836.

43. Misra A, Tyagi P K, Singh M K and Misra D S, Diamond Relat Mater., 2006, 15, 385-388.

44. Cambelli P, Sarno M, Gorrasi G, Sannino D, Tortora M and Vittoria V, J Macromol Sci B Phys.,, 2005, 44, 779-795.

45. Yaghmaee M S, Demeter Z S, Sytchev J, Lakatos J and Katpay G, J Min Metall B, 2003, 39(1-2), 343-352. 